\title{
Rationality in Action. By John Searle. Cambridge: MIT Press, 2001. 303 pages, ISBN 0-262-19463-5. Hardback \$35.00.
}

\section{Curran F. Douglass \\ University of Kansas}

John Searle's Rationality in Action (2001) is an important new book on the theory of rational action. Searle's book is structured primarily as a critique of certain aspects of "the classical model" of rationality. In the introduction there are two sentences in which he acknowledges the classical model as "a pretty good model" of rationality; but this part goes by pretty fast, so if you missed it or if you skipped the introduction, you wouldn't think that there was very much he liked about classical rationality. Actually, he doesn't say much by way of characterization of the classical model, except that it is like chimp rationality ${ }^{1}$. We are, on this model, just very clever chimps, he asserts, except that we humans go in for more long range planning.

Specifically, Searle takes issue with six claims that he attributes to classical rationality. The first is the claim that rational actions are caused by beliefs and desires, in a way that amounts to causal necessitation. Next is that rationality is a matter of obeying rules (i.e., principles). Third, that rationality is a separate cognitive faculty (rather, he claims that some of rationality" basic constraints derive from intentionality). Fourth, the claim that weakness (akrasia) of will can only arise where there is something wrong with the psychological antecedents of action. He further asserts that, on the classical view, there cannot be desire independent reasons for action; and finally, that the set of basic or primary desires must be consistent in order for rationality to operate. He attacks some of these claims at much greater length than others, and these attacks largely constitute the book; but there is something close to a unifying theme. That is "the gap," which he alleges is key to conscious rationality, and is the basis of free will; and I will have most to say about that. 
Searle says quite a bit about intentionality, which appears more basic than rationality; he links intentionality with directedness or aboutness-intentionality is always about something. Building on his earlier work, he makes much of the directions of fit and conditions of satisfaction that intentional states must have. An interesting observation is that the intentional structures of volition and cognition mirror each other-except for the gap of volition. Intentionality requires a pre intentional background of abilities and tendencies that humans share with other animals. Intentionality is itself necessary to rationality of action, which he claims is the basic type; theoretical rationality, though now highly developed in humans, appears as a special case of practical rationality.

One extended argument regards so called desire independent reasons for action. Such reasons-obligations are his main example-he claims are unique to humans and derive from intentional conditions implicit in languages. Specifically, he argues that making commitments is inherent in speech acts of assertion'. It seems to me that this depends on what is meant by 'commitment.' One might argue that true commitments presuppose customs of making promises, including promise keeping and expectations derived from such customary behavior, and that speech acts of assertion are necessary but not sufficient for commitments.

Rationality is to some extent shared with other animals, it appears. We have the following definition.

Rationality in action is that feature which enables organisms, with brains big and complex enough to have conscious selves, to coordinate their intentional contents, so as to produce better actions than would be produced by random behavior, instinct, tropism, or acting on impulse. (2001, p. 141)

So rationality is a goal directed activity, aiming at finding 'the best' or superior outcomes. Searle says this is possible only where there is free choice-in the libertarian sense. Other necessary ingredients include consciousness, desires, intentions, perceptions, a background 
of (animal) abilities and tendencies, language to deliberate and to represent and evaluate relations; and also he includes logical ability. With all this, one has already a self, says Searle.

Now to 'the gap.' Basically, by this Searle means that there is a lack of sufficient causal conditions to our decision making. Reasons could only be part of a causal explanation, he says; in those cases where reasons actually are sufficient, one would have no freedom-such an act would be compulsory, as though one were an addict ${ }^{3}$.

Somewhat surprisingly, Searle says that we do have experiences of 'the gap'-that we sense a lack of causally sufficient conditions when we have to decide. (Or is that just nervous apprehension?) This is the psychological experience of the gap ${ }^{4}$.

Searle takes weakness of will as confirmation that the gap is real. Failure to take 'the gap' into account is what leads to the trouble in trying to explain akratic phenomena, he says. He attributes to the classical model the view that pure cases of akrasia never really occur; that one who acted akratically must not have had a true unconditional judgment (this view is associated with Donald Davidson), or some such denial of proper causal antecedents for action. Actually, akrasia is "as common as wine in France," Searle claims. It is a phenomenon of 'the gap' - which is always there, and there is thus no guarantee that we will always carry through with our resolutions or best decisions.

Why do we deliberate and form intentions, anyway? Searle says that

a large part of the point of these is to regulate our behavior. ... we bring order into our lives and enable ourselves to satisfy more of our long range goals by the formation of prior intentions through deliberation. (2001, p. 234)

Because of our inherent need to regulate our actions, we form intentional states, he says; and sometimes these can come into conflict. Akrasia is such a conflict between intentional states, he says, where "the wrong state wins." The outcome is irrational in that the agent doesn't act on his own best reasons. But there is, he 
says, no necessary logical inconsistency in such cases, nor need one be overwhelmed by a strong desire. That's because of 'tine gap'-with the gap, anything can happen at any time.

But what are we to make of 'tine gap,' and of its special causality? Searle is less certain here; he tentatively endorses what he calls a "unified field approach." This seems to mean that consciousness is not bottom up, but occurs on all levels simultaneously, and in addition consciousness itself seems to have a special causal power. It produces actions, through conscious rationality. He asserts that a self performs an act, but does not cause it. At the same time, he is completely opposed to the idea that the movement of the self as system could be random-that would not comport well with agency.

With respect to causation and the gap, Searle says that it is not conceivable that neurobiological determinism could co occur with psychological indeterminism-that would mean that the conscious rational self was an epiphenomenon, which is very hard to accept, for one thing from an evolutionary point of view (since clearly nature has invested a lot in conscious rationality).

Rather, it must be the case that causation is "systematic," but without causal sufficiency. The totality of micro elements is causally sufficient for the causation of mental states at any time (or else we would have dualism) - yet conscious rationality has influence "all the way down"; a top down causation with which Searle professes to see no problem. He claims that the gap is not between levels of organization, but is across time. At the end, he admits he does not find this explanation entirely satisfactory. It is, he says, an empirical matter.

I don't find it satisfactory either; though I agree that the nature of neurobiological causation is an empirical matter. But his preferred explanation is not very clear, to say the least. If the micro level is causally sufficient for all states and phenomena, and the "unified conscious field" is at the same time separate and can causally influence future states, then how is this supposed to work? It sounds like overdetermination, though Searle would not agree.

Even more dubious is his claim that we actually experience the lack of causal sufficiency in cases where one must decide. How could that be, since we don't experience its opposite? We don't 
experience causal sufficiency, that causal conditions were such that exactly that event or action had to occur. Causal sufficiency is a theory based postulate, rather than something that is experienced. It is much more likely that what we experience is some sense of having now to decide; or perhaps a nervous anxiety associated with that.

Also, other animals share in rationality and consciousness, he admits; do they also have such gaps? If not, what is the basis of human exceptionality? What would be the evolutionary basis for the disappearance of causal sufficiency, in mechanisms which prepare for action (where one would like to assure that superior choices will be made)? Finally, Searle says that rationality and the gap are coextensive - which is to say, that rationality is coextensive with a region of causal insufficiency. But if, as he allows, the gap may turn out to be an illusion, then what of rationality? It would then seem to have no extension; which surely cannot be right.

However, apart from matters of 'the gap,' Searle's account is useful, with several good ideas and interesting suggestions and arguments. Searle connects rationality with intentionality in a way that is important and useful. He observes that rationality is a biological phenomenon, which we share with other animals. $\mathrm{He}$ offers a view of selves as non Humean, biological, unified beingsas animal agents; and reminds us that we need animal abilities to choose and act. He rightly links rationality to freedom (but then he uses the wrong concept of freedom, libertarian freedom, which does not go with his otherwise naturalistic account). He asserts that rationality in action is more fundamental than rationality of theory, the latter having a more recent and subsidiary development. Finally, his views on reasons, particularly his defense of external reasons, is enlightening and useful. Another strength is the general clarity of the writing. All in all, there is much to recommend in the book.

\section{Notes}

1. His example is the chimps of Wolfgang Kohler, who in a famous experiment, got down bananas by setting a box under them, standing on the box, and hitting the bananas with a stick. He seems to limit classical 
rationality to means ends rationality. Actually, 'classical rationality' is something of a misnomer here, at least if by that one means a view derived from classical antiquity; 'the received view' or 'the standard view' might be more accurate.

2. With respect to speech acts of assertion, he seems to have a point: saying that something is true does seem very close to saying "you ought to believe it." But as he notes elsewhere, on the volitional side, not everything runs parallel. There is, as he also says, nothing which stands to intention as truth does to belief.

3. Searle has a libertarian view of freedom, that it is identical with free will which is taken to be an absence of sufficient causal conditions for action. This choice is not well argued for, and doesn't go well with his overall view that mind is a biological phenomenon. In my opinion, that leaves a gap in his account, between compulsion and uncaused choice.

4. Actually, Searle claims that there are three such gaps; they are as follows. First, there is said to be a gap between deliberation and the decision reached-w which is the same as the formation of a prior intention; second, there is another gap between the prior intention and the intention in action that is supposed to derive from it; and third (for actions extended in time) a gap between these intentions and the actual carrying out of the action. These seem to be theoretical rather than experienced, and depend on his theory of intentions. Also, the alleged feeling of 'tine gap' is experiential; whereas the gap implied by free will is metaphysical. 